\title{
O SERVIÇO DE ENFERMAGEM HOSPITALAR - APRESENTANDO ESTE GIGANTE SILENCIOSO
}

\author{
THE HOSPITAL NURSING SERVICE \\ A SILENT GIANT \\ LOS SERVICIOS DE ENFERMERIA HOSPITALARIA \\ PRESENTANDO ESTE GIGANTE SILENCIOSO
}

Giseia Maria Schebella Souto de Moura'
Ana Maria Müllerde Magalhäes"
Enaura Helena Brandāo Chaves

RESUMO: O artigo focalizaa importāncia do serviço de enfermagem nas organizações de saúde, metaforizando sua grandeza com a expressāo "gigante" e seu pouco reconhecimento pela comunidade através do termo "silencioso". A abrangência e a complexidade de seu funcionamento è pontual na efetividade dos processos de cuidado em saúde, no entanto, sua estrutura e organizaçāo è pouco conhecida pelos demais profissionais de saủde e quase que totalmente desconhecida pela comunidade. O serviço de enfermagem congrega grande contingente de pessoal com diferentes niveis de formaçāo. O planejamento, organizaçāo, estrutura e funcionamento deste serviço seguem as diretrizes emanadas da Teoria Geral da Administraçāo e os conhecimentos desta área têm sido cada vez mais utilizados para atingir as metas e objetivos almejados pelas instituições de saúde. $O$ ensaio, contudo, nāo deixa de abordar questões sobre o foco no cliente e qualidade do atendimento. apontando para a necessidade de repensar o modelo administrativo adolado buscando sempre alternativas sistêmicas e contingenciais.

PALAVRAS-CHAVE: serviço de enfermagem, gerenciamento em enfermagem, administraçāo em enfermagem

\section{JUSTIFICANDO OTITULO...}

Pode parecer confuso, aos leitores deste ensaio, o titulo a ele conferido. Os adjetivos de "gigante" e "silencioso" tem sua razāo de ser.

O primeiro, refere-se ao grande contingente de pessoal que integra o serviço, abrangendo de 45 a $70 \%$ de todos os trabalhadores do hospital. Além disto, tern equipes distribuidas em vários locais da instituiçāo e estabelece interaçōes com, praticamente, todos os serviços. O segundo - "silencioso" - tem a ver com a maneira como, ainda nos dias atuais, este trabalho é reconhecido e valorizado pela populaçāo de modo geral. Os clientes das instituiçōes de saúde recebem açōes de enfermagem e, na maioria das vezes, desconhecem como se desenvolve esse processo de trabalho e quem sāoos profissionais que compōem a equipe de enfermagem. Em nossa realidade, percebemos que existe uma cultura de designar como "enfermeiro" todo

' Douforanda em Administraçāo do Programa de Pós-Graduaçāo em AdministraçāoUfRGS. Professora Assislente do Departamento de Assistência e Orientaçāo Profissional da Escola de EnfermagemUURGS. Mestre em Educaçāo pela PUCRS.

2 Professora Assislente do Departamento de As sisténcia e Orientaçāo Profissional da Escola de Enfermagem/UFRGS. Mesire em Educaçāo pela PUCRS. Chele do Seniço de Enfermagem Cirúrgica do HCPA.

${ }^{3}$ Protessora Assistente do Departamento de As sisténcia e Orientaçāo Profissional da Escola de EnfermagemiUFRGS. Mestre em Administração pelo PPGAUFRGS. 
aquele profissional que atua na área da saúde e usa uniforme branco.

Além das razōes histórico-culturais, acredita-se que esta situaçāo se perpetue, em parte, pelo pouco desenvolvimento do marketing na enfermagem.

O termo marketing è aqui entendido, conforme a definiçāo de Erdmann e Erdmann(1996. p.38-9), como "... uma filosofia abrangente de como relacionar dinamicamente qualquer organizaçāo ao seu mercado ou o seu público; è a atividade humana designada para a satisfaçāo das necessidades e desejos através dos processos de troca". Já para Bartels (1988), marketing é uma atividade social ao invés de meramente econōmica, pois é essencialmente uma maneira de encontrar e satisfazer certas necessidades das pessoas.

infelizmente, temos de admitir que o status e a imagem da enfermagem perante a populaçāo, ainda nāo evoluiu da forma como seus profissionais desejariam. Isto aponta para a necessidade da enfermagem repensar a forma como desenvolve o relacionamento com seu mercado, caso contrário, o adjetivo "silencioso" continuará sendo utilizado para caracterizá-lo.

O propósito deste artigo é oferecer uma visāo geral do serviço de enfermagem na área hospitalar. Para tanto, percorrer-se-ȧ uma linha de raciocinio a partir das origens da enfermagem como profissāo. A seguir, busca-se descrever o serviço de enfermagem e suas principais caracteristicas, utilizando como recurso de análise os pressupostos da teoria geral da administraçāo. Num terceiro momento, aborda-se a estrutura e organizaçāo do serviço, apresentando-se alguns exemplos de organogramas com vistas à ilustraçāo. Após, enfoca a equipe de enfermagem e a legislaçāo que regulamenta a formaçāo e o exercicio profissional. Para concluir, sāo apresentadas algumas consideraçōes finais.

\section{A ORIGEM DA PROFISSĀOE SUA ORGANIZAÇĀO COMO SERVIÇO}

Para melhor compreender os serviços de enfermagem nas instituiçōes de saúde, faz-se necessário, entender o próprio desenvolvimento da enfermagem como profissāo. O conhecimento dos determinantes históricos e culturais tem sido um recurso valioso no desvelamentode mitos, tabus e ritos incorporados à prática profissional.

Sabe-se que, nos primórdios da civilizaçāo, os doentes eram cuidados pelos sacerdotes e feiticeiros, pois a concepçāo de doença estava ligada ao poder divino ou diabólico. Com a evoluçāo do conhecimento sobre plantas medicinais, os sacerdotes médicos passaram a delegar a outras pessoas a parte do cuidado do doente que se relacionava ao preparo e administraçāo das drogas, surgindo assim as funçōes de farmacêutico e enfermeiro.

Com o cristianismo, o trabalho de enfermagem passa a ser orientado por um sentimento de amor ao próximo, caracterizando-se por ser benevolente, voluntário e gratuito. Religiosas, viúvas e damas da sociedade cuidavam dos doentes e pobres como forma de purificaçāo de suas próprias almas (ALMEIDA; ROCHA, 1986).

A queda do cristianismo veio comprometer seriamente o cuidado aos doentes. Com expulsāo das religiosas dos hospitais, estes foram obrigados a contratar, em caráter emergencial, profissionais remunerados. Entretanto, com os baixos salários oferecidos e uma carga pesada de trabalho, foram atraidas para este ambiente apenas pessoas que viviam em condiçōes precárias de alimentaçāo e nutriçāo e de moral duvidosa. Segundo Paixaão (1969, p.57) “... o tipo comum da enfermeira era o da bêbada, desordeira, mulher de má vida."

Nos hospitais, durante este periodo de caos, as pessoas trabalhavam sem qualquer forma de organizaçāo e supervisāo. Os doentes eram abandonados ou deixados morrer. Os funcionários, devido às suas condiçōes morais e sociais, extorquiam gor jetas dos doentes.

Com Florence Nightingale deu-se a renovaçāo da enfermagem. Após seu preparo na Instituiçāo de Kaiserswerth, foi trabalhar na Guerra da Crimeiia. O trabalho coordenado por ela, logo se destacou, conseguindo reduzir sensivelmente o indice de mortalidade entre os feridos. Seu conhecimento acerca de epidemiologia, estatistica e liderança foi considerado avançado para a época. 
Posteriormente, outro trabalho seu que merece destaque, foi a fundaçāo de escolas de enfermagem. Tinha como objetivo reformar a enfermagem no mundo inteiro, atraindo para as escolas, jovens educadas e de boa posiçāo social.

Para Almeida e Rocha (1986, p. 41), Florence preocupou-se em "(...) delimitar o espaço social que cada trabalhador da saúde deve ocupar na hierarquia do micropoder hospitalar e, em especial, a preocupaçāo com a hierarquia do pessoal de enfermagem".

Partindo de um modelo de formaçāo profissional com ênfase na disciplina, designava para o treinamento no cuidado direto ao paciente as pessoas provenientes de categorias sociais mais baixas, enquanto que as de categorias sociais mais favorecidas destinavam-se às tarefas de gerência (supervisāo e administraçāo) e de ensino. As primeiras executavam um ţabalho de baixo prestigio social e, conforme cita Silva (1986), eramchamadas de "nurses"; as segundas, chamadas "ladies-nurses", dominavam um tipo de saber mais valorizado socialmente.

Neste mesmo periodo, o hospital passa a ser uma instituiçāo de cura, nāo só para abrigar doentes e necessitados, e o saber médico consolida-se em bases mais fortes, afirmam Almeida e Rocha (1986). Observa-se o surgimento das relaçōes de dominaçāo e subordinaçāo de modo mais intenso, pois os médicos passam a dirigir os hospitais. Desta forma, além de possuir sua hierarquia interna de estruturaçāo do serviço implantada por Florence, passa a ter suas açōes dependentes e subordinadas à prática médica.

Os estudos de Lima (1998), sobre as atividades realizadas pela enfermeira dentro do modelo clinico de atençāo à saúde, revelaram que a enfermeira tem uma funçāo coordenadora das atividades dos demais trabałhadores da equipe de saúde envolvidos no cuidado ao paciente. Este papel gerencial da enfermeira é reconhecido e valorizado pelos demais profissionais. considerando-o imprescindivel para garantir o desenvolvimento do trabalho coletivo.

A evoluçāo da organizaçāo do serviço de enfermagem baseou-se no avanço dos conhecimentos da área de administraçāo, assim como a evoluçāo do cuidado de enfermagem acompanhou os avanços do conhecimento nas áreas da biologia, medicina e tecnologia.

\section{O QUE É O SERVIÇO DE ENFERMAGEM?}

Serviço de enfermagem è a expressāo que tem sido encontrada, tanto nos hospitais quanto na literatura, para designar o que, na realidade, seria o departamento de enfermagem nos hospitais. Entretanto, a expressāo departamento de enfermagem tem sido bem mais utilizada na área acadêmica (como forma de organizaçāo e estruturaçāo de cursos) do que na área de assistência. Aidéia de ter-se um departamento ou serviço de enfermagem tem suas origens na departamentalizaçāo proposta pela Teoria Clássica da administraçāo cuja essência, segundo Chiavenato (1993), está na estrutura e na forma da organizaçāo. A preocupaçāo com a divisāo do trabalho ao nivel dos órgāos que compōem a empresa deu origem aos departamentos nas mesmas. O departamento, para Gulick citado por Chiavenato (1993), existe quando estāo reunidos, na mesma unidade ou setor, pessoas que estāo realizando o mesmo trabalho, pelo mesmo processo, para a mesma clientela e no mesmo lugar.

Assim, transpondo essa proposta para o ambiente do hospital, o ser viço de enfermagem representaria o órgāo responsável pelo desenvolvimento de atividades afins (cuidados de enfermagem aos pacientes), através dos profissionais com formaçāo e competência legalmente reconhecidos pela Lei de Diretrizes e Bases do Ensino e Lei do Exercicio Profissional (BRASIL, 1996. 1986), em consonāncia com os padrōes de qualidade almejados pela profissāo e em sintonia com os objetivos organizacionais.

Outras denominaçōes encontradas: Supervisāo de Enfermagem, Chefia de Enfermagem, Gerência de Enfermagem, Superintendência de Enfermagem, Departamento de Enfermagem e Setorde Enfermagem. De modo geral, tem-se observado, que o termo utilizado para referir-se à enfermagem, segue a mesma linha de terminologia dos demais órgāos, serviços ou departamentos da empresa. 
Um outro ponto de análise do serviço de enfermagem é sua concepção dentro de uma abordagem sistêmica. Se o hospital for considerado um sistema, composto por vários subsistemas, o serviço de enfermagem é um de seus elementos integrantes, que se relaciona com os demais e cujo trabalho tanto exerce como sofre influências destes.

Um exemplo clássico desta situação é o do paciente que necessita estar em jejum para a coleta de exame laboratorial: se a enfermagem não orientar o paciente quanto à necessidade de tal procedimento e não supervisionar o cumprimento do mesmo, certamente o exame não poderá ser coletado ou, se o tiver sido, necessitará de uma nova coleta, retardando o diagnóstico, o tratamento e a recuperação. Isto acarretará aumento de custos tanto no que se refere à assistência ao paciente, como no âmbito social, pois esse individuo não estará contribuindo com sua força produtiva na parcela de trabalho pela qual é responsável e, além disso, prejudicando a disponibilidade do leito para um outro paciente.

O serviço de enfermagem de um hospital é o órgão ou departamento que congrega todo o pessoal de enfermagem, definindo a filosofia e os pressupostos que norteiam a assistência de enfermagem naquela organização. Ele é composto por um grande contingente de pessoal: (60\% segundo GAIDZINSKI, 1991) integrado por diversas categorias profissionais, as quais possuem diferentes niveis de formação e preparo e que, consequentemente, desempenham funções distintas.

O trabalho da enfermagem é profundamente marcado por influência das idéias da "administração cientifica", através da divisão do trabalho e especialização do trabalhador; da "teoria clássica", com o estabelecimento de uma estrutura hierarquizada, com diferentes niveis de chefia, além da utilização de praticamente todos os princípios estabelecidos por Fayol; da "teoria da burocracia" através da utilização de regimentos, regulamentos, manuais de normas e rotinas, caráter formal das comunicações.

A enfermagem é a categoria de profissionais que mais tempo permanece junto ao paciente e maior contato estabelece com ele. Funciona, por vezes, como um elo de ligação entre o paciente e a equipe dos diversos profissionais que o acompanham, recebendo, armazenando e transmitindo uma infinidade de informações entre estes. As observações feitas pela enfermagem, bem como a transmissão destas informações ao profissional competente são determinantes no pronto estabelecimento de um diagnóstico e na definição da terapêutica.

Para Magalhães, Pires e Keretzky (1997), a equipe de enfermagem representa o elo integrador do sistema de informação em saúde, exercendo um importante papel no processo de comunicação de dados das diferentes equipes que atendem ao cliente.

Ainda sob a óptica da abordagem sistêmica, o serviço de enfermagem possui os três componentes básicos: entrada ou input, processamento e saida ou output, além da retroação ou feedback e do ambiente com o qual faz intensa e constante interação. Este cenário pode ser visualizado na figura a seguir:

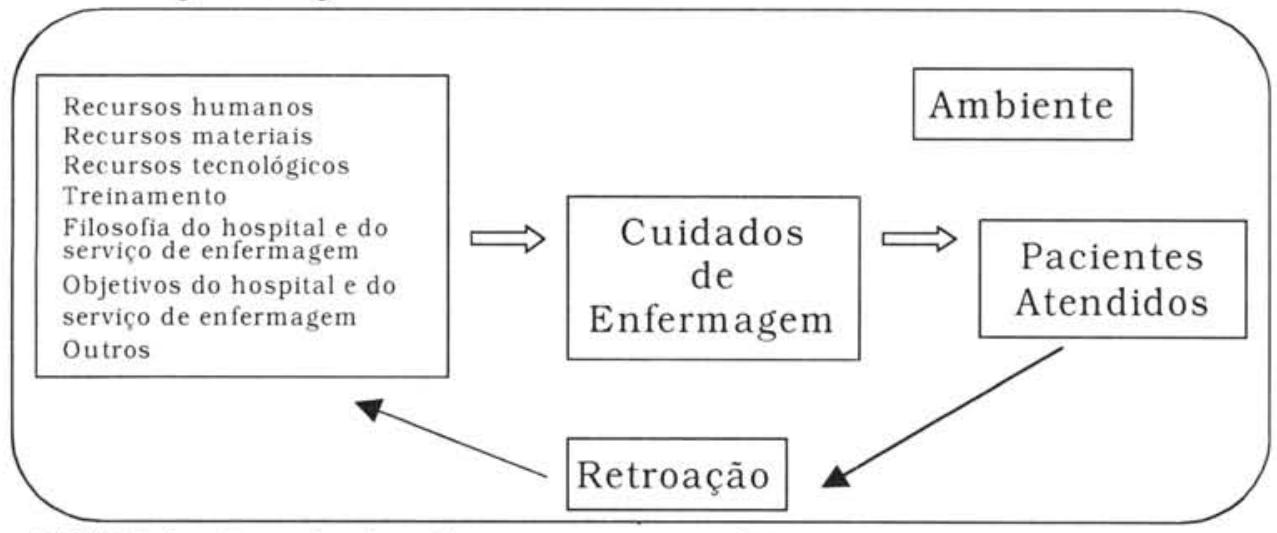

FIGURA 1 - O serviço de enfermagem como um sistema 


\section{CARACTERISTICAS DOSERVIÇO}

Acredita-se que muitas das caracteristicas do serviço de enfermagem já tenham sido citadas no decorrer do texto, como por exemplo:

- Congrega um grande contingente de pessoal;

- Tern seu pessoal alocado em diversos setores do hospital;

- É considerado um sub-sistema do sistema maior que è o hospital;

- Como sub-sistema interage e se interrelaciona com os demais sub-sistemas;

- É hierarquizado, obedecendo a uma cadeia de comando.

Além destas, outras poderiam ser acrescentadas, tais como:

- Congrega várias categorias de profissionais, com diferentes niveis de formaçāo;

- Fragmentado: pois como congrega profissionais com diferentes niveis de formaçāo, legalmente, cada um está habilitado a desenvolver determinadas atividades;

- Desenvolve atividades de diferentes niveis de complexidade;

- Continuidade: o trabalho da enfermagem requer continuidade por diferentes equipes que se alternam em turnos sucessivos;

- Imprevisibilidade: em decorrència das modificaçōes no estado de saúde/doença dos pacientes;

- Interrupçōes: pelas situaçōes que requerem atendimento de urgência ou mesmo de atendimento às solicitaçōes dos pacientes (campainhas):

- Confrontaçāo com o sofrimento;

- Permanència no setor ou status residencial.

\section{ESTRUTURAE ORGANIZAÇÃO}

A estrutura do serviço de enfermagem, como já foi dito, é fortemente influenciada pelos postulados clássicos da administraçāo. Os organogramas utilizados para representar este serviço sāo, em sua maioria, do tipo "linha" ou "linha-staff", demonstrando a hierarquia e a cadeia de comando existentes. Em geral, eles seguem o mesmo desenho do organograma do hospital.A localizaçāo do serviço de enfermagem no organograma geral do hospital evidencia o alcance de seu poder e grau de autonomia nas decisōes. Para ilustraçāo, ałguns tipos clássicos de organogramas estāo apresentados nas figuras 2 e 3 .

\section{ORGANOGRAMA DO HOSPITAL $X$}

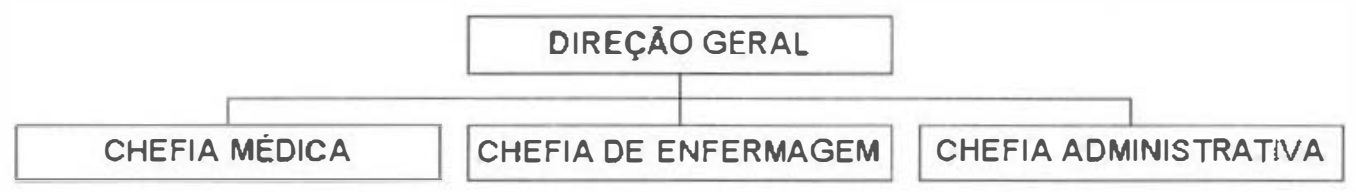

F Guka 2 - Organograma geral do Hospilal X

ORGANOGRAMA DO HOSPITAL Y

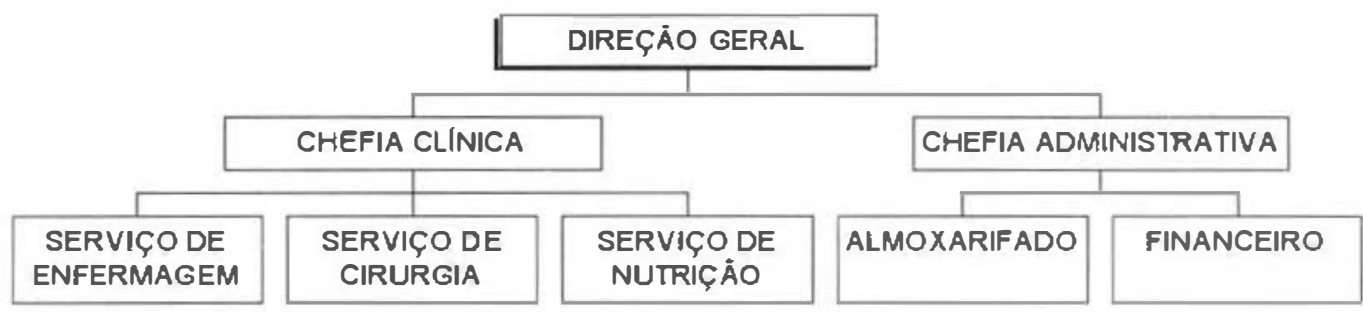

FIGURA 3 - Organograma geral do Hospital Y 
As instituições de saúde, geralmente, são estruturas complexas e se traduzem em organogramas representados por vários níveis hierárquicos. Atualmente os estudos de administração vêm apontando para a necessidade, cada vez maior, de diminuir os niveis hierárquicos gerando o achatamento e a reformulação na representação físicas das estruturas organizacionais.

Com a evolução do conhecimento em administração novas propostas de organograma foram surgindo, tentando representar graficamente os pressupostos norteadores do trabalho nas empresas. Assim, surgiram as pirâmides invertidas, organogramas circulares indicando trabalho em equipe ou mesmo organogramas em forma de alvo onde o cliente era colocado no centro. Segundo Cohen (1998), os organogramas sofreram verdadeiras transformações, passando a serem representados por figuras geométricas complicadissimas.

O serviço de enfermagem, sendo um departamento integrante de uma organização maior, tem adotado uma estrutura semelhante a essa. Assim, hospitais com organogramas hierárquicos reproduzem em seus departamentos também o mesmo tipo de organograma.

Internamente, o serviço de enfermagem também sofre uma especialização nos dois sentidos: vertical e horizontal. A vertical ocorre quando há necessidade de acrescentar mais niveis de chefia na estrutura para melhorar a supervisão, acarretando, segundo Chiavenato (1993), um desdobramento da autoridade. A especialização horizontal ocorre quando há necessidade de se agrupar pessoas com especialização em determinada atividade ou área de conhecimento (Figuras 4 e 5 ).

ORGANOGRAMA DO SERVIÇO DE ENFERMAQEM - HOSPITALZ

COORDENAÇÂO DE ENFERMAGEM

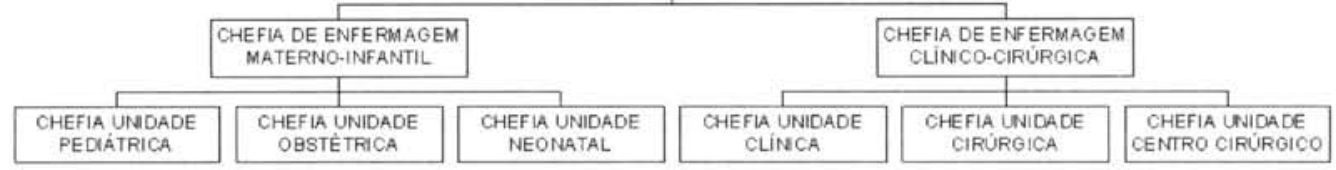

FIGURA 4 - Organograma do Serviço de Enfermagem - Hospital Z

Pode-se dizer que não existe um tipo ou tamanho ideal de estrutura ou de departamentalização na enfermagem. Ela estará na dependência do tamanho do hospital, complexidade dos cuidados, especialidades por ele atendidas, tipo de paciente, filosofia e objetivos do serviço de enfermagem, grau de centralização/descentralização das decisões, dentre outros.

Organogramas circulares também são utilizados para representar o serviço de enfermagem. Para Marx e Morita (1998, p.49) "o organograma circular vem atender às necessidades atuais do Gerenciamento do Serviço de Enfermagem, voltado à visão mais humanística, em que o paciente é o centro das atenções e a equipe atua em parceria para melhor atendê-lo. Um exemplo é apresentado pelas autoras citadas e foi reproduzido com adaptações.

DRGANOGRAMA DO SERVIÇO DE ENFERMAGEM - HOSPITAL W

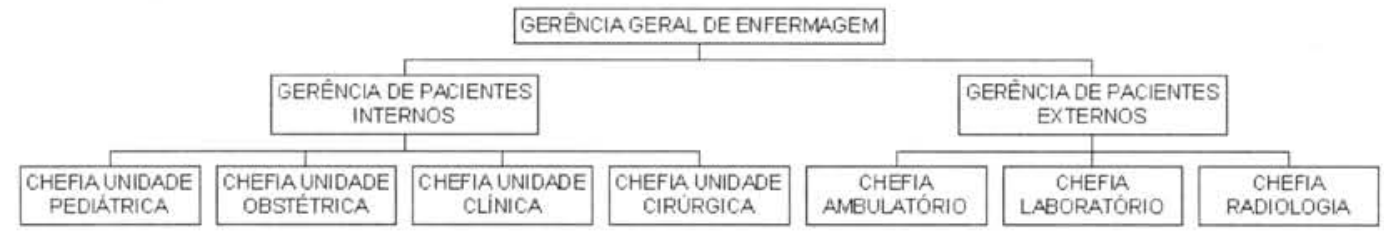

FIGURA 5 - Organograma do Serviço de Enfermagem - Hospital W 


\section{Organograma Circular III}

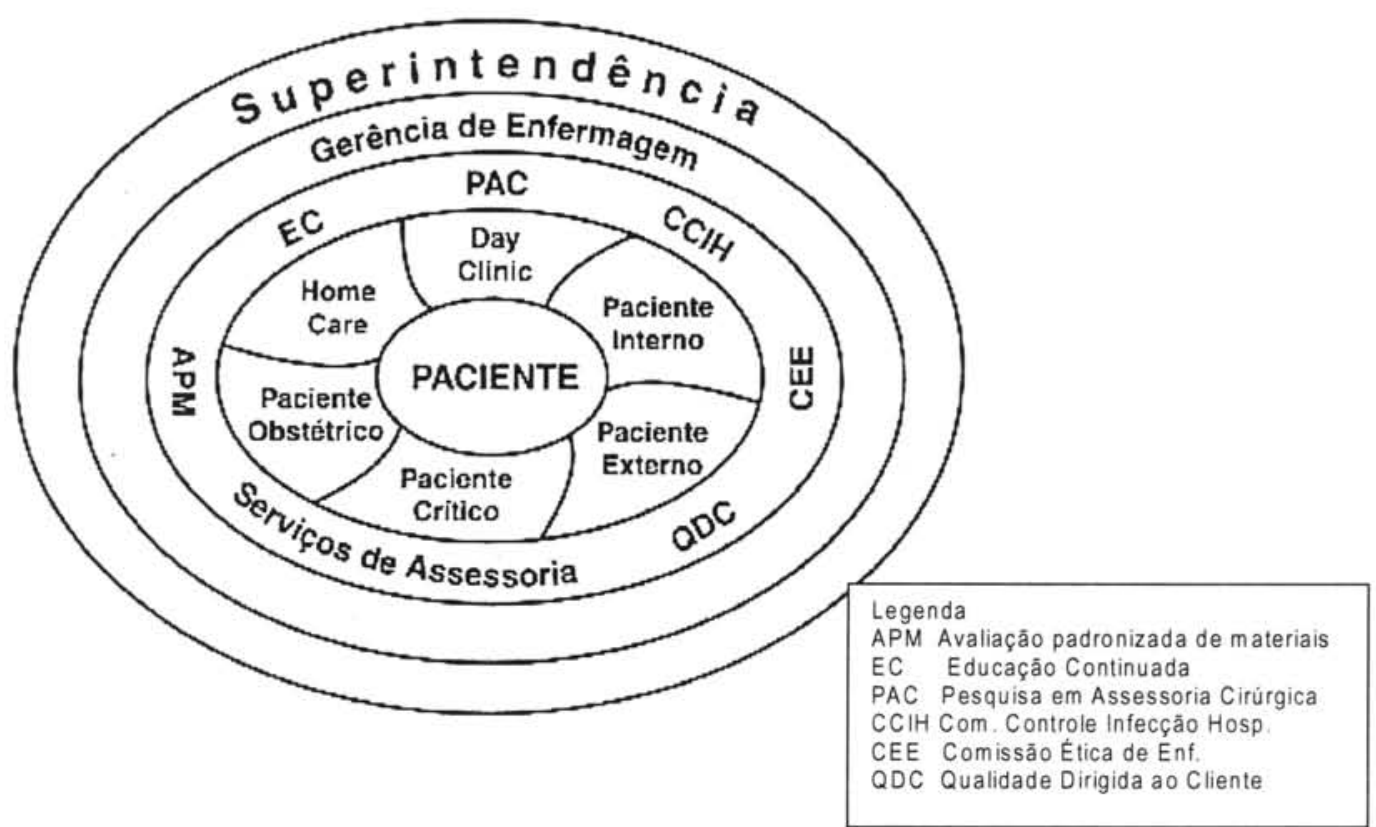

No que diz respeito à organização percebe-se uma forte influência das idéias da Teoria da Burocracia, através da adoção de regimentos, regulamentos, manual de normas e rotinas, uniformidade de procedimentos e comunicação escrita. Para Kurcgant(1991, p.9) "A valorização das normas e regras parece ser, entretanto, o enfoque da Teoria da Burocracia que mais tem influenciado a prática da enfermagem, influência essa que, na verdade, constitui um dos fatores que têm contribuido para uma prática administrativa estanque, baseada em regras e normas obsoletas com poucas perspectivas de mudanças." A autora menciona ser esta prática uma disfunção da burocracia.

As organizações hospitalares e outros serviços de saúde vêm buscando atualizar-se nas novas tendências de gestão, mas entendemos que estas instituições ainda necessitam avançar no sentido de modernizar-se saindo de um modelo mecanicista e desenvolvendo o lado humano até então em plano secundário.

Neste contexto, vemos reproduzidos nos serviços de enfermagem, muitas das dificuldades organizacionais que contribuem para uma gestão mais estática e menos flexivel, conforme já destacado por Kurcgant(1991).

Entendemos que os serviços de enfermagem, em grande parte, ainda estão representados e funcionam baseados em uma estrutura hierárquica vertical com vários niveis. Pode-se dizer que estes modelos têm dificultado a adoção de estratégias de gestão mais participativas e flexiveis, que pressupoem um processo decisório mais ágil, rápido e menos centralizado.

\section{OS PRESSUPOSTOS NORTEADORES DO CUIDADO DE ENFERMAGEM}

Cabe ao serviço de enfermagem estabelecer a filosofia do cuidado de enfermagem que deverá prestar e dentro desta responsabilidade estabelecer os objetivos e metas a serem alcançados. 
O cuidado de enfermagem orienta-se combase na visāo holistica do individuo, concebendoo como um ser que reage como um todo frente aos fatores agressores ou ameaçadores do ambiente. Esta resposta ao ambiente é entendida como sendo própria de cada individuo. Assim, cada um deve ser compreendido e cuidado considerando-se sua individualidade. Nesta concepçāo, nāo pode ser negligenciado o contexto da familia e da comunidade na qual está inserido.

Outro aspecto que nāo poderia ser esquecido è a humanizaçāo do cuidado. Açōes simples como referir-se ao paciente pelo nome (e nāo pelo número do leito) e tratá-lo com cordialidade, respeito e consideraçāo sāo alguns exemplos que podem ser facilmente implementados.

$E$ interessante observar que esses aspectos integram o elenco de expectativas dos pacientes quanto ao seu atendimento. Segundo Marquis e Huston (1999), além da qualidade técnica, os pacientes dese jam cortesia, atendimento rápido à chamada da campainha, atmosfera de alegria e atitudes dos funcionários que demonstrem sua sensibilidade diante do inconveniente da hospitalizaçāo. Estes aspectos evidenciam padrōes de qualidade com base na opiniāo do cliente. As autoras ainda alertam que, na grande maioria das vezes, os padrōes de qualidade na área da saúde contemplam as expectativas dos profissionais e nāo dos pacientes.

O foco no cliente è uma abordagem bastante utilizada na área da indústria, onde o cliente participa do desenvolvimento de novos produtos, com vistas a uma maior adequaçāo desse às suas necessidades. O atendimento de enfermagem focado no cliente, isto é, baseado em suas necessidades e expectativas, è uma proposta defendida por alguns pesquisadores.

Matsuda, Évora e Boan (2000, p.16) em uma pesquisa realizada na área hospitalar, mostram que ainda existem dificuldades para implantaçāo desta proposta devido "... à escassez de recursos humanos, a falta de incentivos da instituiçāo e de valorizaçāo pela equipe dos aspectos interacionais com o cliente". Para os autores, este modelo que contempla a participaçāo do cliente no seu atendimento, é ainda pouco difundido entre profissionais da enfermagem, carecendo de discussōes mais amplas.

Atualmente tem sido muito discutido, tambèm, o sistema primary nursing. Segundo Manthey (1980), este método propōe que o trabalho seja organizado de tal forma que todo o paciente tenha uma enfermeira responsável por sua hospitalizaçāo, definindo os cuidados a serem prestados em comum acordo com ele ou seus familiares. Para Marx e Morita (2000, p.116), o foco principal deste sistema "... é a qualidade do cuidado prestado".

Primarynursingé um modelo de prestaçāo de serviços para pessoas e. portanto, busca contemplar nāo só a dimensāo técnica do cuidado, mas, tambèm, a dimensāo humana que envoive a execuçāo de um procedimento. As duas dimensōes - técnica e humana - estāo presentes em todos os momentos da interaçāo no hospital, sendo que às vezes uma se sobrepōe à outra.

Muito se tem discutido a respeito dos diferentes modelos de organizaçāo do trabalho de enfermagem e a partir disso algumas áreas já estāo definidas : a visāo filosófica sobre o que é enfermagem e quais sāo os papéis desempenhados pelo enfermeiro, que o objeto central de sua atenção é o paciente, buscando dentre modos diversos aqueles que melhor os ajudem a se sentirem confortáveis, minimizando os danos e promovendo um aito nivel de bem-estar.

\section{A EQUIPE DE ENFERMAGEM}

Para Cianciarullo (2000), a enfermagem tem sido uma profissāo que se desenvolveu inserida num grupo de trabalho denominado equipe de saúde, composto por vários profissionais, no qual a classe dominante sāo os médicos. A equipe de enfermagem tem uma divisāo social e técnica caracterizada pelodesenvolvimento de açōes realizadas por profissionais com diferentes niveis de formaçāo: o enfermeiro com nivel superior; o técnico de enfermagem, com curso regular e nivel médio de $2^{\circ} \mathrm{grau} ; 0$ auxiliar de enfermagem com curso regular e formaçāo de $1^{\circ}$ 
grau e, ainda, atendentes com um curso rápido ou, às vezes, sem nenhum preparo formal. Estes últimos, nāo mais reconhecidos por lei (7498/86), como profissionais de enfermagem.

No Brasil, na década de 70, houve uma forte expansāo do mercado de trabalho em saúde, impulsionando a formaçāo de recursos humanos de enfermagem que respondessem às novas práticas e tecnologias em saúde. Neste periodo a maior taxa de crescimento foi de técnicos de enfermagem; no entanto, ainda hoje o maior contingente de profissionais de enfermagem è da categoria de auxiliares com formaçāo de nivel médio.

Segundo dados do Conselho Regional de Enfermagem (COREN-RS, 2000) o Brasil conta com 603.270 profissionais de enfermagem, sendo que $14,45 \%$ sāo enfermeiros, $15,52 \%$ sāo técnicos de enfermagem e $70,02 \%$ são auxiliares de enfermagem.

A última Lei de Diretrizes e Bases da Educaçāo Nacional (BRASIL, 1996) nāo prevê a formaçāo de auxiliares. Assim sendo, a partir desta lei o curso de auxiliar passa a ser considerado curso livre, nāo possuindo reconhecimento profissional. Os auxiliares formados anteriormentea 1998 têm amparo legal e estāo legalmente habilitados ao exercicio profissional, desde que inscritos no conselho de sua regiāo.

A Lei n. 7.498, (BRASIL, 1986), dispōe sobre o exercicio da enfermagem, definindo esta atividade como privativa do enfermeiro, técnico de enfermagem, auxiliar de enfermagem e parteiro. O exercicio só é permitido aos profissionais inscritos no Conselho Regional de Enfermagem da respectiva regiāo. Os requisitos de cada categoria bem como suas competências encontramse especificadas no texto da referida Lei.

No estado do Rio Grande do Sul, o Conselho Profissional elaborou a Decisāo COREN/ RS No 103/00 que dispōe sobre a normatizaçāo das atribuiçōes dos profissionais de enfermagem. Esta decisāo foi elaborada considerando que a Lei do Exercicio Profissional abrange de forma ampla as atribuiçōes de cada categoria, nāo especificando claramente as atividades. Alèm disto, tambèm considerou o Parecer N. ${ }^{\circ} 840 / 98$ do Conselho Estadual de Educaçāo que veda a constituiçāo de novas turmas para o Curso de Auxiliar de Enfermagem a partir da data de aprovaçāo do parecer.

O quadro de profissionais no estado do Rio Grande do Sul, segundo dados do COREN/ RS (2000) é de 51.800 no total. Destes $14,61 \%$ sāo enfermeiros; $13,66 \%$ de técnicos e $71,17 \%$ de auxiliares de enfermagem. Esta proporçāo è ilustrada no gráfico a seguir:

\section{GRÁFICO 1 - PROFISSIONAIS DE ENFERMAGEM RIO GRANDE DO SUL - 2000}

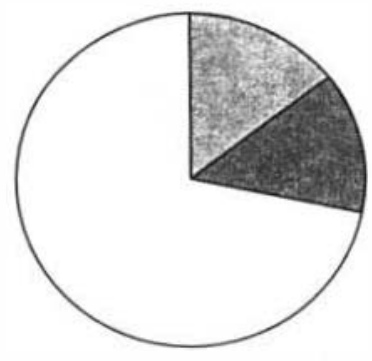

Qenfermeiros

口técnicos

口auxiliares

Fonte: COREN/RS. 
Em relaçāo aos demais estados, a situaçāo do contingente de pessoal de enfermagem configura-se da seguinte forma:

QUADRO 1 - ESTADOS BRASILEIROS COM MAIOR NÜMERO DE PESSOAL DE ENFERMAGEM - 2000

\begin{tabular}{|l|r|r|r|r|}
\hline \multicolumn{1}{|c|}{ REGIĀO } & ENFERMEIROS & TÉCNICOS ENF. & AUXILIARES ENF. & \multicolumn{1}{c|}{ TOTAIS } \\
\hline Såo Paulo & $\mathbf{2 5 . 0 8 5}$ & 16.294 & 145.755 & 187.134 \\
\hline Rio de Janeiro & 11.931 & 25.145 & 57.018 & 94.094 \\
\hline Rio Grande do Sul & 7.612 & 7.115 & 37.073 & 51.800 \\
\hline Minas Gerais & 5.899 & 8.616 & 33.661 & 48.176 \\
\hline Bahia & 4.935 & 2.786 & 21.690 & 29.411 \\
\hline
\end{tabular}

Fonte: COREN/RS

Como mostra o quadro acima o estado do Rio Grande do Sul posiciona-se em número de profissionais de enfermagem em terceiro lugar. No que diz respeito ao número de enfermeiros, percebe-se que o estado de São Paulo é o que possui maior contingente, seguido pelo Rio de Janeiro.

\section{CONSIDERAÇO̊ES FINAIS}

Buscamos com este estudo retratar a importância do serviço de enfermagem nas organizaçōes de saúde, metaforizando sua grandeza com a expressāo "gigante" e seu pouco reconhecimento pela comunidade atravês do termo "silencioso".

A abrangência e a complexidade de seu funcionamento è pontual na efetividade dos processos de cuidado em saúde, no entanto, sua estrutura e organizaçāo è pouco conhecida pelos demais profissionais de saúde e quase, totalmente, desconhecida pelos clientes.

O serviço de enfermagem hospitalar, como foi descrito ao longo deste ensaio teórico, è complexo, abrangente e congrega grande contingente de pessoal com diferentes niveis de formaçāo. Como nāo poderia deixar de ser, o exercicio de sua atividade está regulamentado em Lei, bem como a formaçāo específica de cada um dos elementos integrantes da equipe de enfermagem. Mudanças recentes no que se refere à educaçāo nacional vêm implicando em alteraçōes da composiçāo da equipe.

O planejamento, organizaçāo, estrutura e funcionamento deste serviço seguem as diretrizes emanadas da Teoria Geral da Administraçāo. Os conhecimentos desta área tem sido cada vez mais utilizados para atingir os objetivos almejados pelo hospital e pelo próprio serviço de enfermagem.

A gerência do serviço de enfermagem implica nọ envolvimento com trabalho, pessoas e ambiente; relacionamento interpessoal; produçāo e avaliaçāo de serviços (prestaçāo de cuidados): tomada de decisāo, comunicaçāo; elaboraçāo de escalas; passagem de plantāo; registros; capacitaçāo e desenvolvimento de pessoal; apreciaçāo do desempenho; dentre outros aspectos. Os custos relacionados com o processo de cuidar, sejam atravês do cuidado direto ou indireto, devem ser estabelecidos e continuamente revisados.

O ensaio, retomando discussōes sobre foco no cliente e qualidade do atendimento. aponta para a necessidade de repensar $o$ atendimento que vern sendo prestado de forma a melhor contemplar essas questōes. Contudo, considerando todos os aspectos que o permeiam, 
é indiscutivel a contribuiçāo que este gigante silencioso pode trazer à consecuçāo dos objetivos da organizaçāo hospitalar.

ABSTRACT: This article shows the importance of the nursing service in the health organizations. The metaphor "giant" will be used to describe the extent of this service, and the term "silent" will be used to refer to the little acknowledgment the nursing service receives from the community. The extent and complexity of the nursing assistance is vital for the effectiveness of the processes of health care, however its structure and organization is unknown by the community. The nursing service congregates a great number of personnel with different levels of education. The planning, organization, structure and operation of this service follow the principles of the General Theory of Administration. Knowiedge from this area has also been used to help health institutions to achieve its goals and objectives. This study also approachès the client and the quality of health assistance, pointing out the need of reexamining the administrative model adopted and looking forward to systemic alternatives.

KEYWORDS: nursing service, nursing management, nursing administration

RESUMEN: el articulo refleja la importancia de la atención enfermeria en las organizaciones de salud, metaforizando su grandiosidad con la expresión "gigante" y su poco reconocimiento por la comunidad a través del término "silencioso". La amplirud y la complejidad de su funcionamiento es puntual en la efectividad de los procesos de cuidado en salud, sin embargo, su estructura y organización es muy poco conocida por los demás profesionales de salud y casi que totalmente desconocida por la comunidad. El servicio de enfermeria un gran número de personal con distintos niveles de formación. El planeamiento, la organización, la estructura y funcionamiento de ese servicio siguen las directrices emanadas de la teoria general de la administración y los conocimientos de ese campo han sido cada vez más utilizados para alcanzar las metas anheladas por las instituciones de la salud. EI ensayo, sin embargo, no deja de tratar los temas que conciernen al cliente y a la calidad de la atención y apunta hacia la necesidad de repensar el modelo administrativo que se adopta, para buscar alternativas y soluciones a nivel práctico y teórico.

PALABRAS CLAVE: servicio de enfermeria. gerencia en enfermeria, administración en enfermeria

\section{REFERENCIAS BIBLIOGRAFICAS}

ALMEIDA, M. C. P: ROCHA, J. S. Y. O saber de enfermagem e sua dimensão prálica. São Paulo: Cortez, 1986.

BARTELS, R. The history of markefing thought. Columbus: Publishing Horizons, 1988.

BRASIL, Lei de Diretrizes e Bases da Educaçāo Nacional. N. 9394. de 20 de dezembro de 1996.

BRASIL, Lei n. 7.498 de 25 de junho de 1986. Dispōe sobre a regulamentação do exercicio da enfermagem e dá outras providências. Diário Oficial da Uniāo. Brasilia, p.9271-5, 26 jun. 1986.

CHIAVENATO, I. Introd ução à teoria geral da administração. 3. ed. Sāo Paulo: McGraw-Hill, 1993.

CIANCIARULLO, T.I. Instrumentos básicos para o cuidar: um desafio para a qualidade da assistência. São Paulo: Atheneu, 2000.

COHEN. D. Não se fazem mais pirâmides como antigamente. Exame, n.13, jun. 1998. p. 90-92.

CONSELHO REGIONAL DE ENFERMAGEM DO RIO GRANDE DO SUL. Informativo do Conse/ho Regional de Enfermagem do Rio Grande do Sul, n.9, ago. 2000. 
Legislaçāo. Porto Alegre: COREN-RS. 2001.

CONSELHO ESTADUAL DE EDUCAÇĀO. Parecer n. 840/98. Disponivel em: www.ceed.rs gov.br

ERDMANN, R.; ERDMANN, A. L. O marketing e a enfermagem: a conquista de uma imagem encantadora do profissionalismo. Texto e Contexlo. Florianópolis, v. 5, n.2, p.35-42, jul./dez.1996.

GAIDZINSKI, R. R. Dimensionamento de pessoal de enfemagem. In: Kurcgant. P. Administraçāo em enfermagem. Sāo Paulo: EPU, 1991.

KURCGANT, P. Administração em enfemagem. São Paulo: EPU, 1991.

LIMA, M.A.D. daS. O trabalho de enfermagem na prod uçäo de cuidados de saude no modelo clinico. Ribeirāo Preto, 1998. 216 p. Tese (Doutorado) - Escola de Enfermagem de Ribeirāo Preto. Universidade de Sāo Paulo.

MAGALHĀES, A.M.M.; PIRES, C.; KERETZKY,K. Opiniāo de enfermeiros sobrea passagem de plantāo. Revista Gaúcha de Enf., Porto Alegre, v. 18, n.1, p.43-53, jan. 1997.

MANTHEY, M. A prática de primary nursing. Boston: Blackwell Scientific Publications. 1980.

MARQUIS, B.; HUSTON, C. Administraçāo e liderança e menfermagem. Porto Alegre: Artes Médicas, 1999.

MARX. L. C.: MORITA, L. C. Manual de Gerenciamento de Enfermagem. Sāo Paulo: Rufo, Editores Associados, 1998. p. 49.

Competências gerenciais na enfermagem - a prática do sistema primary nursing como paråmetro qualitativo da assistência. Sāo Paulo: BH Comunicaçāo. 2000.

MATSUDA, L.; ĖVORA, Y.; BOAN. F. O foco no cliente no processo de atendimento de enfermagem: visāo dos enfermeiros. Administraçāo Nursing, out. 2000.

PAIXĀO, W. História da enfermagem. 4.ed. Rio de Janeiro: Bruno Buccini. 1969.

SANTOS, E. et al. Legis/açāo em enf ermagem. atos normativos do exercicio e do ensino de enfermagem. Sāo Paulo: Atheneu, 1997. 